\title{
LA IMPORTANCIA DE LAS ARTES EN EL DESARROLLO INTELECTUAL Y CREATIVO: HACIA UN SISTEMA CULTURAL
}

\section{THE IMPORTANCE OF THE ARTS IN THE INTELLECTUAL AND CREATIVE DEVELOPMENT: TOWARDS A CULTURAL SYSTEM}

\author{
Marina Gacto Sánchez : Universidad Católica San Antonio de Murcia. España. \\ mgacto@ucam.edu
}

\section{RESUMEN}

En el presente estudio se aportan algunas reflexiones sobre la importancia de la formación artística en la sociedad actual. Para ello trazamos un análisis de su valoración en épocas anteriores, abordando paralelamente la consideración social de los artistas plásticos y los factores que han influido en la revalorización de su figura a través de la literatura biográfica. En esta época de confusión sobre qué es el arte y cuál debe ser su función, es importante volver la vista atrás hacia nuestro pasado cultural y realizar una breve historia del arte. De este modo, podremos comprender mejor su situación actual.

PALABRAS CLAVE: Arte, sociedad, artista, creatividad, estatus, educación, biografía.

\section{ABSTRACT}

In this paper we reflect on the importance of arts education in nowadays society. We establish an assessment on these historical issues taking as reference the social consideration of the plastic artist, as well as the factors that have influenced its appreciation through the study of the biography genre. In this time of cultural confusion we usually wonder what art and its purpose in society is; so it is important to look back to our cultural heritage and historical background. Therefore, we can better understand the current situation of the art system.

KEY WORDS: Art, society, artist, creativity, status, education, biography.

\section{Cómo citar el artículo:}

Gacto Sánchez, M. (2014). La importancia de las artes en el desarrollo intelectual y creativo: hacia un sistema cultural. Revista de Ciencias de la Comunicación e Información, 19, 37-53.

http://doi.org/10.35742/revistacccomunicacioneinformacion.2014.19.37-53

\footnotetext{
1 Marina Gacto Sánchez: Personal Docente Investigador. Universidad Católica San Antonio de Murcia. Departamento de Educación.
} 


\section{INTRODUCCIÓN}

El universo de la educación y la formación artística ha perdido valor en las reformas recientemente acaecidas en la sociedad contemporánea. Para entender su importancia en la sociedad actual nos remontamos a su valor anterior e intentamos reposicionar su situación hoy en día.

El arte es un potente vehículo de trasmisión. Su correcto aprendizaje promueve el desarrollo holístico, tanto a nivel emocional, sensorial e intelectual como creativo. Las enseñanzas artísticas han sido frecuentemente ignoradas en los diversos niveles educativos. Esta marginalidad es el resultado de dos valoraciones opuestas pero complementarias. En la alta modernidad, el arte en la educación se desplaza paulatinamente en las instituciones educativas a un lugar accesorio vinculado al tiempo libre, la recreación y el adorno e incluso a la oferta del mercado; restringiéndose su uso a festividades escolares y ceremonias cívicas (Aguirre, 2009).

La plástica es considerada una actividad marginal en el currículo por dos razones claves:

- El escaso valor que lo artístico tiene en la sociedad, puesto que se entiendo como un saber no productivo.

- La poca valoración que los lenguajes expresivos tienen en relación a otras áreas de conocimiento; potenciando la divergencia y creación frente a procesos mentales de dependencia e imitación propios de la escuela actual.

La paradoja es que la actividad plástica en nuestro país no se comprende como el producto de la utilización de un lenguaje, sino como la acumulación de técnicas y destrezas. Esto se debe fundamentalmente a dos motivos (Delgado, 2003):

- La falta de preparación de los docentes en Expresión Plástica, puesto que no existe una formación especializada dentro de los estudios universitarios en pedagogía.

- La confusión conceptual y pedagógica existente, que se ve agravada en nuestro país por diversas situaciones históricas.

Como herederos de la mentalidad Occidental hoy en día valoramos la ciencia positiva, apostando por lo fáctico, conmensurable, lo susceptible de controlar, la eficacia y el productivismo. Nos enfrentamos a la racionalidad funcional (Habermas, 1987) que se esfuerza por monopolizar el ambiente social y cultural. Así, los lenguajes simbólicos de la cultura (corporales, sonoros, visuales, gestuales) se van diluyendo y se están quedando relegados negando un ámbito fundamental de la condición humana: la expresión de lo subjetivo y lo sensible, que sólo el arte puede suministrar. Se trata pues de reconocer la particularidad de lenguajes en cada campo y lo que cada uno aporta a la construcción del individuo. "La obra de arte expone valores a la experiencia directa del sujeto, que se desarrolla a partir de un acto intuitivo- perceptivo frente a ella" (Schwartz, 2006) alejándose de los valores verificables científicos y vinculándose así a la expresión y comunicación.

Una vez abordada la situación actual, trazaremos algunas claves en el despliegue de este campo; momentos en los que la práctica artística ha sido motivo de reflexión 
y análisis. Para ello es necesario comprender que el arte remite a un universo en el que se integran conceptos, teorías, prácticas, instituciones y políticas, en estrecha relación y constante transformación $Y$ que como tal, también nos confronta con el empleo de términos cotidianos como "artista- artesano", "obra de arte- artesanía", "folclore- arte popular". En este sentido, utilizamos el término pintor para referirnos del mismo modo a uno de brocha gorda y a Miguel Ángel. Esta cuestión es tratada por Calvo Serraller (2011, p. 113) al comparar la extenuación del propio Miguel Ángel al pintar la Sixtina subido a un andamio con el relato de Thomas Bernhard titulado "El Pintor" que forma parte de su libro póstumo "Acontecimientos y relatos".

El proyecto de educación en artes contemporáneo no es superior a dos siglos, aunque las tramas sobre el arte se han construido desde hace milenio son el nacimiento de civilizaciones primigenias como la Egipcia o Mesopotámica. Esa noción reciente y moderna de bellas artes, que se relaciona con el siglo ilustrado, es la que ha impactado en nuestros proyectos educativos como veremos a continuación.

\section{OBJETIVOS}

El presente trabajo tiene como objetivo la reflexión y el análisis de la situación de las artes plásticas en el actual sistema cultural. Trazamos algunas de las claves en el despliegue de este campo, momentos en los que la práctica artística es reflejo de los cambios históricos acaecidos, y analizamos los factores que han influido en la apreciación actual de la misma.

\section{METODOLOGÍA}

Se han utilizado como métodos de investigación el método teórico y el analíticosintético. Se trata de un estudio ensayístico que ha sido presentado dentro de la I Jornada Internacional de Desarrollo Personal celebrada en la Universidad Católica San Antonio bajo la dirección de la Dra. Beatriz Peña.

\section{RESULTADOS}

\subsection{Enfoques y definiciones sobre el fenómeno artístico}

El arte es un proceso humano fundamental. Todas las sociedades se han expresado a través del arte y todas las personas han trasladado sentimientos y emociones a través de una forma artística. El arte es una actividad dinámica y unificadora con un gran potencial en materia educativa. La expresión artística requiere de procesos constantes de asimilación y proyección: absorber a través de los sentidos una gran cantidad de información, mezclarla con el yo psicológico y transformar en una forma nueva los elementos que parecen convenir a las necesidades estéticas del artista en ese momento.

Tal y como sugiere Lowenfeld (1987, p. 41) la sociedad se interesa cada vez más por las fuentes de energía y conservación. De modo paralelo, la mayoría del público afirma conocer lo que le gusta en el terreno del arte y pone en duda el valor de las nuevas formas artísticas experimentales. Parece extraño darse cuenta de que un 
sector de muestra sociedad obtiene aprobación, pero otro sector se le condena por sus investigaciones. El artista, como el científico, intenta comprender lo desconocido en su búsqueda de la verdad: ambos tienen un empeño común por entender la realidad. Con frecuencia se considera la capacidad artística como algo con lo que se nace, algo que acude de forma intuitiva a un individuo sensible. Han existido dudas considerables acerca de si puede enseñarse el arte.

El arte desde una perspectiva social y antropológica puede ser considerado como un fenómeno cultural, de carácter universal que afecta a todas las personas, grupos sociales y culturas. Es quizás uno de los fenómenos más complejos que comprende la cultura como una todo (Alcina, 1982). Si entendemos la cultura como un sistema, el arte forma parte del mismo y por tanto está en relación con las demás manifestaciones culturales (Read, 1970), aunque dependiente siempre de algún aspecto concreto y especialmente vinculado a los modos de trasmisión cultural. De este modo el arte puede ser también comprendido como un elemento de expresión, más que elemento de comunicación o lenguaje.

Gelbach (1990) afirmaba que el arte constituye en sus formas de manifestarse uno de los tópicos educativos más fascinantes, esto es debido a varias razones que apuntamos a continuación. El arte es una de las formas de expresión que está presente en cada civilización humana, y además es comprendida como el legado de la misma. El concepto de Arte es tan amplio como su propia definición, comprendida su práctica como una actividad individual al menos en su carácter conceptual. La habilidad de su aprendizaje está en relación con las aptitudes personales, lo que dificulta su evaluación y proceso de enseñanza.

Una de las cuestiones más obvias desde el punto de vista social es la dificultad de hablar de Arte sin un producto dotado de tal significación cultural (Locke, 1991) y es que la definición que pedagógicamente se ha considerado de artes es una peculiar categoría emic de la moderna civilización euro americana en la cual a los niños se les inculca en la escuela la idea de que artes es una categoría de actividades y productos que se contrapone a la categoría de lo no artístico. Aprenden a creer, en otras palabras, que ciertas pinturas, esculturas, canciones, danzas y cuentos no son arte (Harris, 1990).

El arte puede ser definido desde diferentes vertientes de estudio que presentamos:

- Semánticamente proviene del término griego techné, con el que se aludía a la destreza para realizar algo. Su traducción romana, bastante literal en cuanto a su significación fue ars, que dio lugar a la raíz de las palabras que lo identifican en todas las lenguas romance. Ambas raíces se estudiarán posteriormente para identificar la valoración de esta actividad en épocas pasadas.

- Antropológicamente se relaciona la manifestación productiva de una cultura o civilización y estudia la complejidad de los mundos artísticos contemporáneos.

- Política y económicamente se refiere al valor del mismo desde una perspectiva crematística vinculada a los ejes de poder. 
- Sociológicamente se reivindica la especificidad del lenguaje artístico y de sus códigos visuales vinculando éstos a los grandes cambios económicosociales (Hauser, 1975).

- Psicológicamente interesándose por los efectos que produce estética o artísticamente el producto sobre la audiencia. La percepción visual como instrumento dominante de esas relaciones, la intuición como parte fundamental del conocimiento, las propiedades de las experiencias del espacio y del tiempo y su importancia para las artes son algunas de las ideas desarrolladas por este tipo de estudios (Arnheim, 1986).

\subsection{La práctica artística y desarrollo personal: breve reflexión histórica}

\subsubsection{El legado de los antiguos}

Una de las expresiones más cercanas a nosotros es la que aconteció en Grecia bajo el nombre de techné. La filiación del concepto arte con respecto a la noción de técnica es clara: arte procede del latín ars, que a su vez traducción del griego techné. Para esa sociedad significaba más que hoy para nosotros, En el siglo VI a.C. se refería a cualquier actividad humana que requiriese destreza y habilidad, tanto manual como mental. Era un saber razonado- no improvisado, podría serlo la navegación, la cacería, la herrería o la poesía. La antigua techné equivale a la actual maestría, technites era por tanto el término para designar a los expertos.

Pero no se trataba sólo de prácticas al servicio de la religión o de un ritual, sino que servían como parte del programa de formativo de los ciudadanos. Los filósofos reflexionaron sobre ellas, y las clasificaron en dos grupos según fueran útiles o produjesen placer. Platón y Aristóteles también teorizarán sobre ellas. Para Platón estarían las techné mimetiké, que quedan inscritas en la imitación de la aparienciamoviendo al engaño y siendo denostadas y por otro lado las techné, como actividad humana práctica y la filosofía como formación teórica. Para Aristóteles la techné imitan la naturaleza- estando por debajo de esta- y las technai implicarán modo de hacer inteligente, asociado a lo útil. Estos debates de la alta antigüedad acabarían organizando el conocimiento según las artes manuales o vulgares- porque exigen trabajo físico que es propio de siervos- y las artes liberales o intelectuales. Legándonos hasta hoy en día la dicotomía entre la teoría y la práctica, el conocimiento y la acción.

En la Baja Edad Media esas artes manuales pasaron a denominarse mecánicas. En el siglo $\mathrm{V}$ dc el retórico Marciano Capella integraría las siete artes liberales en: gramática, retórica, dialéctica, aritmética, geometría, astronomía y música. Siendo ordenadas por Boecio más tarde según trivium y quadrivium. De las artes mecánicas tenemos escasas referencias porque apenas son nombradas. Esta organización se diferencia en su enseñanza puesto que las liberales se enseñarán por medio del magister y la palabra, organizándose para las mecánicas el sistema gremial donde la base de la práctica consistía en hacer objetos útiles en esos talleres artesanales. Su aprendizaje comenzaba a los 8-9 años en el taller del maestro, el cual vestía- daba vivienda y alimentaba. Este mundo artesanal tenía mucha reglamentación y fuertes sanciones, no ofrecía las libertades actuales de las que goza cualquier trabajador. 
El reconfigurar de esta situación se da desde 1400 cuando los artífices tendrán que someterse a los mercaderes, pero el sector de artistas se mantendrá en contacto directo con sus más fieles clientes: iglesia y nobleza. Estos trabajarán mediante encargos, pero los artesanos trabajaran en círculos de consumo generalizados.

Artistas como Alberti, Da Vinci que defiende la pintura como cuestión mental o Miguel Ángel, no se pinta con manos sino con la cabeza. Ligaban su trabajo a lo inteligente y al mundo de la geometría o matemática a partir de la creación de perspectiva en la obra. Estos artistas eran conscientes de la necesidad de romper con lo establecido por los gremios y para ello crearon estudios de discusión que posteriormente se convertirían en academias. En las que se lucharía buscando la libertad que les negaban los gremios.

La obra que nos mostrará las condiciones de trabajo del artista serán "Las vidas de los más excelentes arquitectos, pintores y escultores italianos desde Cimabue a nuestros tiempos" de Giorgio Vasari. Un diccionario biográfico donde mostrar el lugar relevante que ocupaban y su formación privilegiada. También funda Vasari la Academia de las Artes del Dibujo en 1562, integrando el sustento teórico y el saber hacer, dispuesta a polemizar con respecto a la superioridad de su saber en relación con otros campos.

Estas prácticas tienen una gran consecuencia: se distancian de los oficios artesanales dando sustento científico a sus saberes. Parece que escultores, pintores y arquitectos quedarán hermanados por el propio dibujo, aunque si nos fijamos en la terminología el termino escultor será utilizado dos siglos en formarse, siendo hasta entonces los statuarii (piedra), encausti (cera), fictores (arcilla) o sculptores (madera).

\subsubsection{El siglo XVIII: la aparición de la noción Bellas Artes}

Tal y como hemos visto, con anterioridad al siglo XVIII los términos "artista" y "artesano" se usaban indistintamente y la palabra artista se aplicaba no sólo a los pintores y compositores, sino también a los zapateros o herreros, así como a los alquimistas y a los estudiantes de las artes liberales. No existían artesanos o artistas en el sentido moderno, todos construían sus obras de acuerdo con una techné o ars, es decir, un arte/ artesanía. Abrams denominó a este cambio "revolución copernicana" en el concepto de arte: "En un solo siglo (...) el modelo de construcción fue sustituido por el de la contemplación, que trataba los productos de las bellas artes como (...) objetos de atención extática" $(1989,140)$.

En la segunda mitad del siglo XVIII el abate francés Batteaux (1747) aporta el término bellas artes: distinguiéndolas de las ciencias y de los oficios artesanales. Así en el siglo XVIII las bellas artes se convirtieron en referentes del buen gusto, propio de la burguesía, siendo las artesanías dotadas de un sentido utilitario y de gusto ordinario, para el vulgo. Pero esas bellas artes, indicadores de refinamiento sociales, querrán ser imitadas por todas las clases sociales. Poco después, y de la mano de Baumharten vendrá la estética, disciplina filosófica interesada en la experiencia y la representación de lo sensible. 
A partir de mitad XVIII comenzamos a ver la posibilidad de una educación en el arte, por el arte y la estética. Schiller, Kant o Wincklemann abogan por el protagonismo que el arte y los artistas deben tomar en el cambio social. Con la llegada del concepto de genio en el siglo XIX se comienza a vislumbrar otro panorama dominado por la subjetividad y la inventio, entrando en juego la sensibilidad romántica. Siendo decisivo la singularidad del autor al crear la obra. A comienzos del siglo XIX también se dividió la antigua idea de función en las artes de tal modo que se atribuyó a las bellas artes un papel espiritual trascendente en tanto que reveladoras de una verdad más elevada o en cuanto que auténticas medicinas del alma.

La mayoría de los artesanos trabajaba antes por encargo de patrones cuyos contratos a menudo especificaban contenido, forma y materiales y preveían un lugar específico y un propósito para la pieza acabada. De modo similar, los escritores profesionales pasaban gran parte del tiempo copiando, tomando notas y escribiendo cartas para sus empleadores. Por añadidura, el trabajo artístico era a menudo una tarea cooperativa en la que intervenían muchas personas.

En España la situación del artista será también distinta, no tenemos grandes artistas escritores ni biografías de artistas como tales hasta el siglo XVIII. La creación de la Academia de Bellas Artes se promulgó en 1752 para defender la práctica artística, dotando de nobleza al artista y exención fiscal, y para separar el campo entre artesano y artista. Pero la situación se modificará cuando ambos compartan espacio docente, los consiliarios tomarán el control de la institución y en 1783 Carlos III declaraba los oficios mecánicos honestos y honrados, sin perjudicar para "goce y prerrogativa de la hidalguía" (Gállego, 1976).

\subsubsection{El fin de la modernidad y la situación actual.}

Todo esto contrasta con las normas dominantes de nuestro sistema del arte, donde el ideal no es la colaboración inventiva sino la creación individual. Las obras pocas veces son concebidas en relación al espacio en el que van a ser expuestas sino que existen por ellas mismas y la separación de las obras con respecto al contexto funcional conduce al ideal de una atención silenciosa y reverencial como la que se observa en una sala de conciertos o museo de arte. Un facto clave en la descomposición del viejo sistema de arte fue la sustitución del mecenazgo por el sistema del arte y del público de clase media.

El sistema moderno de las bellas artes ha dominado la cultura americana y europea desde principios del siglo XIX pero algunos artistas y críticos se han resistido a aceptar sus principios que oponen el arte a la artesanía, el artista al artesano, lo estético a lo utilitario. Algunos autores Hogarth, Rousseau, Wollstonecraft rechazaron la distinción entre artistas y artesanos y la diferenciación entre lo estético y lo instrumental, pese a que tales distinciones estaban vigentes en su época. Igualmente se manifestaron Emerson, Ruskin y Morris, quienes atacaron las dicotomías arte/artesanía y arte/vida. Posteriormente, muchos artistas del siglo XX, entre ellos los Dadaístas y Duchamp ridiculizaron con la ironía tales principios.

Hasta ahora no hemos abordado la dimensión más importante del arte: el sentimiento. El arte no es solamente un conjunto de conceptos e instituciones sino también algo en 
que las personas creen, una fuente de satisfacción, un objeto afectivo. Aquellos que aprecian la idea de que el arte bello es una construcción reciente marcada por intereses de género y clase, comprenderán que forma parte de una conspiración hostil que apunta a desacreditar uno de nuestros valores más elevados.

Dada la ambigüedad que posee la palabra "arte" en minúscula, los dos sentidos a menudo quedan marcados por las letras mayúsculas: arte en general por oposición a Arte. Pero poner mayúsculas plantea sus propios problemas. Consideremos el parágrafo inicial de una de las historias de las artes visuales más populares, la "Historia del arte":

En realidad no existe nada semejante al Arte. Sólo hay artistas. Antaño eran hombres que cogieron un puñado de polvos de colores y garabatearon las formas de un bisonte sobre las paredes de una caverna... No hay problema en que llamemos a estas actividades arte siempre y cuando tengamos presente que esa palabra puede querer decir cosas diferentes en épocas y lugares diferentes y seamos conscientes de que el Arte con mayúscula no existe. El Arte con mayúscula se ha convertido en una especie de espantajo o de fetiche. (Gombrich, 1984, p. 4).

Aunque en ocasiones el término arte sea definido como un producto general, otras veces se le otorga una serie de significados particulares más relacionados con unas habilidades, productos o especificaciones que con una forma especial de conocimiento (Engel y Dobbs, 1983). Esto hace que en cualquier ámbito pero especialmente en el educativo, esta materia sea tratada en términos de oferta y demanda, convirtiéndose en un mero "adorno" del sistema escolar actual. Gadamer (1967) relaciona su escaso valor social con el inmenso progreso obtenido por la ciencia moderna natural como consecuencia del manifiesto deseo de racionalización de la sociedad actual que lleva a la valoración de los estudios científicos y tecnológicos como únicos procesos positivos para la sociedad.

La definición de los términos "hombre de oficios", "artesano" y "artista" tiene también una historia compleja. William Morris hablaba elocuentemente de "trabajador manual", otorgándole un honor y dignidad no presentes en la expresión "artesano". El moderno sistema de arte fue el resultado de la conjunción de muchos factores: algunos de ellos son de alcance general y de desarrollo gradual; otros son más restringidos e inmediatos; algunos son principalmente intelectuales y culturales; otros son sociales, políticos y económicos. La conjunción fue gradual, despareja y cuestionada, pero una cosa es cierta: antes del siglo XVIII, ninguna de las modernas ideas del arte bello, del artista y de lo estético, como tampoco el conjunto de prácticas e instituciones que asociamos con ellas, estaban integradas dentro de un sistema de normas mientras que, después del siglo XVIII, se dan las principales polaridades conceptuales y las instituciones del renovado sistema del arte, y desde entonces se las tiene por admitidas como principios regulativos. Sólo después que el moderno sistema del arte se hubo establecido como ámbito autónomo podemos preguntarnos qué es realmente el arte y cuál es su relación con la sociedad.

Danto en "Después del fin del arte" (1997, p. 114) hace una alegación a favor del relato de la inevitable emergencia del sistema del arte. A pesar de ello, no considera 
lo estético como parte de la esencia del arte sino sólo como una visión meramente contingente que surge en el siglo XVIII. También está convencido de que esa polaridad entre arte y artesanía es esencial, aunque en la cultura occidental se produjo después del Renacimiento.

Posteriormente, se produjo el cisma entre el Arte cuya esencia era estética y la artesanía, como labor manual, pero ambas siguieron estando ligadas a la imitación. Hasta el advenimiento del movimiento moderno, tras el cual los artistas se embarcaron en busca de la esencia del arte, no vemos un intento de cambio por parte del propio artista. Posteriormente, con la llegada del arte pop en los años sesenta del siglo pasado y el arte conceptual, se llegó a la conclusión de que no había una única manera de hacer arte. El arte ya había revelado su auténtica naturaleza: algo que hace una afirmación y al mismo tiempo se encarna en ella de manera autoconsciente. Tras esta revelación sobre la esencia del arte, se reveló también la polaridad que enfrentaba el arte a la artesanía: el profundo significado frene a la mera utilidad, el genio contra la mera habilidad. Como expresa Danto, esto supone que el arte ya no tiene una dirección narrativa. Este el significado de su controvertida frase "el fin del arte", que simplemente hace alusión a la búsqueda de su esencia. Algo que nos llevaría a un tercer sistema del arte más allá del antiguo.

\subsection{La concepción del ser creativo: nacimiento del genio y su influencia histórica}

Los hombres del Renacimiento fueron conscientes de su independencia y creatividad. El filósofo Marsilio Ficino defendió que el artista "inventa" sus obras; el teórico de la arquitectura y pintura Alberti, que preordena; Rafael, que conforma el acuerdo a su idea; Leonardo, que emplea formas que no existen en la naturaleza; Miguel Ángel, que el artista plasma su visión en lugar de imitar la naturaleza; Vasari que a la naturaleza se la conquista por el arte, como natura vinta dall'arte (Tatarkiewicz, 1987). Sin embargo, pese a estas aportaciones, en el siglo XVI el término más aproximado a la actividad creadora es el de genio utilizado para denominar a quienes por su autoridad interdisciplinar no dependían de libros o teorías. Este término no estaba ligado a lo artístico o estético, sino que denominaba a aquellos que debían sorprender amenamente por su inventiva en la resolución de problemas de ingeniería e ingenio, y que debían asombrar, a su vez, por espectacularidad y gracia. En otras palabras, se trata de las características de todas aquellas circunstancias con las que hoy día tratamos de describir la creatividad.

Sin embargo en el siglo siguiente el término genio parece describir los rasgos extraordinarios de los científicos. La evolución de la palabra continúa, a lo largo de la historia, identificando con ella a las personalidades con ciertos rasgos de espiritualidad, como tratando de identificar en la genialidad una manifestación participativa de la divinidad.

Hacia el siglo XVIII, el concepto de creatividad fue apareciendo con mayor frecuencia en teoría del arte. Iba unido al concepto de imaginación, que en aquel período estaba en boca de todos. Anteriormente, Baltasar Gracián describió la práctica artística "como si de una actividad creadora se tratara: completa la naturaleza, la embellece y a veces la supera" (Tatarkiewicz, 1987). 
Finalmente, con el progreso de las ideas ilustradoras y con el desarrollo de los estudios de la personalidad en psicología, se buscan mayores razones externas para su descripción y ello hace que entre en desuso. Actualmente ya no es fácil calificar de genialidad sustantiva a cualquier actividad humana.

Tatarkiewicz atribuye un triple origen al concepto creatividad. Un origen era lingüístico: la expresión "creación" estaba reservada, en el uso contemporáneo, a la creación ex nihilo que era inaccesible al hombre. La segunda fuente era filosófica: la creación es un acto misterioso, y la psicología de la llustración no admitía misterios. El tercer origen era artístico: los artistas de la época debían estar sujetos a reglas, y la creatividad parecía irreconciliable con las reglas.

En el siglo XIX comenzó la polémica sobre la creatividad en las ciencias y en la naturaleza. Esta actitud más propia de un progreso intelectual, ideológico y social pronto pondría a prueba las jerarquías del status artístico. Sin embargo la verdadera y definitiva recuperación del término y el concepto Creatividad podríamos asegurar que vendría de la mano de la Psicología con el bagaje de su polémica consideración semántica. El requisito "a partir de la nada" desapareció. La creatividad de acuerdo con esta nueva construcción, significaba la fabricación de cosas nuevas en lugar de fabricar algo a partir de la nada.

Es en el siglo XIX cuando el término creator se incorporó al lenguaje del arte. Pero entonces se convirtió en la propiedad exclusiva, en nuestra cultura occidental, del arte: creador se convirtió en sinónimo de artista. En el siglo XX, la expresión "creativo" empezó a aplicarse a lo largo de toda las culturas occidentales; se comenzó a hablar de la creatividad en las ciencias, en política, educación, en tecnología, etc. Surgió y se institucionalizó la creencia de que no sólo los artistas pueden ser creativos, sino también las personas activas de otros campos de la cultura. La creatividad es posible en todos los campos de la producción humana. La ampliación del alcance del concepto alteró en realidad su contenido. Los psicólogos la identificaban con una conducta humana manifiesta. Si bien el origen real del concepto había sido la religión su status actual se debe a la psicología. El concepto artístico no guarda ningún vínculo ni relación con ese origen religioso, salvo el hecho mismo del origen semántico e influencia argumental por ósmosis.

Conceptuar el real sentido del término creatividad ha provocado enormes dificultades lingüísticas. Ni siquiera en la actualidad el término creatividad aparece en los diccionarios oficiales de cada lengua, la española sólo recientemente y tras largo debate académico lo ha incluido. Sólo lenguas de origen eslavo como el polaco tienen términos que asumen la semántica de la creación, de este modo stwórca podría ser traducido como la creación a partir de la nada crear a partir de la nadaalgo comparable únicamente a la figura de un Dios religioso- y twórca sería equiparable al término de creatividad artística (Arañó, 1994).

\subsection{Valoración social del artista a través de la literatura biográfica}

Los diversos escritos biográficos, tratados de arte y pequeñas redacciones, en muchos casos actualmente dispersos y faltos de sistematización son, sin embargo, instrumentos documentales muy útiles para reflejar con nitidez lo que la sociedad del 
pasado pensaba de sus propios artistas. Al estudiar cómo los contemporáneos de los artistas juzgaron su existencia a través de lo que hoy denominamos relato biográfico, se observa una repetición historiográfica de cierto tipo de prejuicios o nociones estereotipadas que tienen un origen común. La imagen del artista surge a partir de su legado, pero el hecho de que perdure su nombre no depende de la perfección de su logro artístico sino del significado directamente ligado a la obra de arte y las raíces de la biografía están en la búsqueda de la inmortalidad por parte del ser humano, buscando la reputación de los hechos terrenales (Linton, 1945).

Las biografías del antiguo Egipto tenían una función sacra, mantenían la fama asegurando el paso a la eternidad. Sus propósitos eran biográficos puesto que buscaban mantener la reputación del individuo pero son consideradas protobiografías por la autoglorificación que las define. En Babilonia y Asiria, las biografías siguieron un curso más secular que las egipcias. Siguieron manteniendo ese carácter de escritura en primera persona que las acerca a nuestra concepción de la autobiografía y serán los reyes quienes marquen sus memorias a través de las crónicas.

A pesar de que la civilización Griega fue la primera en individualizar al ser humano y darle una libertad haciéndolo consciente de su potencial, su sentimiento sobre el destino que rige el devenir del ser humano provocó un relativo desinterés sobre el género biográfico. Pocos escritos defienden la memoria de héroes individuales, sino que se basan en la búsqueda del hombre ideal. Teofrasto publicó "Los caracteres", creando una lista de comportamientos específicos e ilustrando tipos. En lugar de encajar el comportamiento del individuo en un molde prefabricado, mostró como las acciones realizadas pueden servir para generalizar sobre su personalidad. Se convirtió en el líder de la escuela peripatética a la muerte de Aristóteles, quien abogaba no por crear una lista con las características del retratado, sino por explicar sus actos como resultado de su personalidad. Otro escritor perteneciente a esta escuela fue Aristoxenus de Tarentum, cuyo trabajo es importante para el desarrollo de la biografía. Es considerado el primer biógrafo con un punto de vista crítico para cada personaje según sus intereses, ya que alabó la labor de Pitágoras pero desacreditó la labor de otras figuras clave. Además de discutir sobre la carrera del individuo aportaban datos sobre sus orígenes, formación y educación. En época Helenística los escritores decidieron reaccionar contra las biografías peripatéticas y su estilo poco correcto. Antigonus de Carystus, en 240 a.C. escribió sus "Vidas de los filósofos", pero sus biografías aburridas y desorganizadas no superaban lo artístico de las anteriores aunque eran más exactas. Teniendo en cuenta este devenir histórico del género, el hecho de que la biografía de algunos artistas griegos, como Zeuxis o Apeles, haya sobrevivido por encima de su obra es una muestra de la importancia que su figura tuvo en la antigüedad. La imagen del artista reflejada en la cultura griega es considerada un hito que no se recuperará como entidad dependiente hasta finales de la baja Edad Media, pero cuya fama perdura hasta la actualidad.

La gran enciclopedia de Plinio el Viejo, "Naturalis Historia", inspirada en tradiciones biográficas anteriores, se ha considerado a menudo un puente a través del cual se transmitieron esta serie de anécdotas estereotipadas sobre la vida del artista. No obstante, sabemos que en la Antigüedad los artistas no estaban dotados de ningún 
talento especial socialmente reconocido. De hecho, su posición se caracterizaba por la falta de independencia, la mitad de los derechos ante la ley y una estimación de su rango extraordinariamente baja. Esta tradición venía de antiguo, y la falta de aprecio de su actividad quedaba definida por su labor manual, que los convertía en una profesión servil, así que como por el hecho de que el arte, según teorías platónicas, era mímesis, imitación de la naturaleza. Así, el artista solo podría proporcionar un lejano reflejo del mundo de las ideas. Panorama, cada vez más complejo, si tenemos en cuenta las excepciones contenidas en la historia y en las biografías de algunos personajes, ciertamente excepcionales, como el caso de Fidias. El proceso contra él al final de su vida tiene diversos motivos, uno de los cuales se refiere al hecho, sacrílego para sus contemporáneos, de colocar su propio retrato en el escudo de la sagrada imagen de Athenea Parthenos.

Sin embargo, a principios del siglo IV a. C. esta situación comenzó a cambiar, y la estimación de pintores y escultores los llevó a convertirse en protagonistas de sus propias biografías aunque continúan las actitudes enfrentadas respecto a su posición social. Un siglo antes, tal y cómo había expuesto el propio Jenofonte en las Memorabilia socráticas, se extendió la idea de que la obra de arte no tenía por qué ser una mera imitación de la naturaleza con sentido claramente peyorativo, sino que, según afirmaba "la obra de arte es superior a la naturaleza porque corrige los defectos de las obras individuales de ésta, a la que compara con una imagen de la belleza recién creada e independiente" (Panofsky, 2004). La figura suprema de la tradición biográfica antigua será Plutarco, en sus "Vidas de Nobles Griegos y Romanos", resumía la cultura de la antigüedad. Fue el primer gran exponente del género con un nuevo punto de vista pero utilizó los métodos y organización anteriores. Enfatizaba el carácter sobre el oficio, una cuestión que siempre ha sido criticada. En sus juicios sobre el arte y los artistas opina que las artes plásticas y la literatura son agradables, pero el artista por sí mismo no nos estimula a imitarlo, será su virtud de sus actos la que atrae nuestra admiración y nos incita a imitarlo. Plutarco exalta así la figura de Fidias, al que cita como brazo derecho y amigo personal de Pericles. Para él, el embellecimiento a través del arte incita a las personas que lo contemplan a actos moralmente buenos.

La influencia de Plutarco no fue plausible hasta el Renacimiento y sirvió de modelo para las biografías de la época moderna. A finales del siglo catorce Filippo Villani escribiría "Vidas de llustres Florentinos", título que influyó a Vasari y donde la influencia de Plutarco y Suetonio se dejaba sentir. También influyó decisivamente en contemporáneos como Tacitus, que fue considerado el biógrafo más importante durante la época final del Imperio. Suetonio, contemporáneo de Plutarco, escribió las "Vidas de los doce Césares" con gran profusión de anécdotas y teniendo como referente a Cornelio Nepote, que había cultivado este género en época romana. Siguió la tradición Helenística, sus relatos se hicieron muy famosos puesto que estaban saturadas de episodios lujuriosos, perversiones y acontecimientos brutales. Además, al heredar de la cultura literaria griega las Laudatio funebris, la redacción de vidas sobre grandes personajes en relación a su fama se generaliza progresivamente. Estas ideas, pasaron a convertirse en dogma en la filosofía de Plotino y fueron introducidas en el pensamiento medieval para florecer como rasgo permanente en las biografías renacentistas. Pero en la antigüedad clásica, todos 
estos rasgos no llegaron a reflejarse en las biografías de los artistas ni en su valoración social.

En el Renacimiento Italiano, especialmente ya en el Cinquecento, es cuando puede apreciarse cómo la inventio se convierte en la máxima aspiración del pintor. La imitación pasa a un segundo plano, el éxtasis artístico se convierte en protagonista y, con ello, la visión interior del artista, su inspiración, pasa a primer plano. Panofsky demostró que la idea de la voz interior del artista se halla enraizada en las filosofías platónicas y neoplatónicas. Esta adulación hacia el artista cristalizó en una observación de Durero, que definió la creatividad artística como "crear igual que Dios", cuyo paralelismo italiano es la definición del artista como alter deus por Alberti (Wittkower y Wittkower, 2006).

A partir del Renacimiento los biógrafos comienzan a referirse al origen divino de su genio, y en este punto el biógrafo se convierte en profeta y la biografía en mito. Los biógrafos pretenden convertir al artista en héroe, y empiezan a compararlo con Dios, analogía que va encaminada a sublimar la creatividad artística. Ya en pleno siglo XVII el artista será visto como un ser superior a su público y los neófitos críticos de arte considerados como enemigos. Finalmente, todos estos conceptos eclosionan por completo en el siglo XIX, donde el término artista se convertirá en sinónimo de genio.

No obstante, si tenemos en cuenta que a lo largo de la historia se contempla una evolución sobre la visión del artista en paralelo a un cambio de actitud en la sociedad seremos capaces de entender el enfoque de algunos historiadores como Benedetto Croce que, en su "Filosofia dello Spirito", proclama la necesidad de crear una "historia del arte sin los artistas". El espectador como tal no pertenece a la vida estética a no ser que cree o exprese lo que contempla, por lo que se reduce a la figura del creador o artista. En este sentido, también ha sido cuestionado el papel del individuo en la historia a través del estudio de la biografía. Calverton afirmaba en los años veinte que es la situación cultural la que produce personajes famosos, negando así la grandeza del ser humano y la necesidad de biografía artística. Otros como Thomas Carlyle aseguraran que son los hombres los que pueden cambiar el desarrollo de los hechos, afirmando la posición del individuo y su importancia dentro de la literatura y la historia. La influencia de Hegel, las teorías de Darwin y el determinismo económico de Karl Marx provocaron también una menor atención hacia la individualidad. Por todas estas razones no merecía la pena escribir biografías. La figura más importante dentro de la literatura biográfica europea la encontramos en el británico Dr. Johnson. La importancia de su obra no sólo se basa en su obra escrita y en su análisis de los problemas a la hora de acercarse al género, sino que su propia vida fue motivo de inspiración para otros muchos escritores. Defendió la igualdad del ser humano y por ello sentía que cualquiera se podía sentir identificado con el personaje protagonista al leer una biografía. Por estas razones defendió el valor práctico de la biografía y sintió que no debía referirse sólo a personajes famosos, sino que cualquiera que cualquier vida tendría un interés. Con sus "Vidas de poetas", introdujo en el género una nueva línea que no se centraba en biografías políticas o religiosas. Con James Boswell, y su "Life of Samuel Johnson", 1791, se culminó el desarrollo de este tipo de relatos biográficos. 
Pero lo que en este estudio nos importa es la personalidad estética del artista, y no la empírica. En consecuencia, la superioridad artística del creador en la literatura viene siempre inspirada de los relatos renacentistas que hunden sus raíces en el lenguaje de la antigüedad clásica y que elevan la figura del artista dentro de la sociedad en la que conviven.

El proverbio every painter paints himself, dicho que se hizo popular por Filippo Baldinuci, (Sohm, 2002) biógrafo de Caravaggio, sugiere la incorporación de su retrato en sus pinturas. Así, a través de estas obras realizadas por el artista, podemos conocer la personalidad del autor. Para Gombrich la obra de arte también es un reflejo del coleccionista porque el connossieur quiere identificarse con el artista. Colin Eisle afirma que lo que eres es lo que tienes, y que siendo la imagen un arma poderosa, símbolo de la libertad de uno, es usado para elevar el status social del que la produce y de quien la compra (Eisle, 1987).

\section{CONCLUSIONES Y DISCUSIÓN}

Nuestro sistema educativo no favorece el desarrollo del lenguaje visual y limita el tiempo para la expresión individual, favoreciendo así la dependencia y la imitación. Nos encontramos con una confusión conceptual, pedagógica y didáctica relacionada con las artes, lo que significa una dificultad adicional para el profesorado que, en su mayoría, desconoce los fundamentos del lenguaje visual -sintaxis visual-, la expresividad y los operadores creativos de manejo (Acaso, 2006). La gama más amplia de las prácticas culturales y las identificaciones que se recomiendan como resultado de las reformas multiculturales plantea dificultades prácticas a los futuros profesores de arte, como, por ejemplo, la forma de enseñar patrimonio cultural y el tipo de contenidos culturales a incluir (Hargreaves, 1996).

No obstante, de modo inversamente proporcional a esta desvalorización permanente del currículo escolar y a la escasa conciencia social (Efland, 2002), nos encontramos ante una realidad socio-educativa particular: un momento de "pluralismo cultural", en el que museos, galerías, lugares de exposiciones y ferias de arte aprovechan el lenguaje artístico para exponer información con el fin de facilitar el intercambio comunicativo entre el artista y su público potencial. Es por tanto ese lenguaje el que necesitamos enseñar a los estudiantes para enseñarles a entender la significación de las imágenes, su interpretación y su producción. En esta línea los tres aspectos principales en la competencia de los niños con las artes visuales destacan la percepción, conceptualización y producción (Eisner, 1995 y 2004).

En esta época de confusión sobre qué es el arte y cuál debe ser su función, es importante volver la vista atrás hacia nuestro pasado cultural y realizar una breve historia del arte. De este modo, podremos comprender mejor la situación actual y los temas contemporáneos.

Tras los cambios acontecidos en el siglo XVIII, los artistas en todos los contextos parecieron querer romper las fronteras del arte y superar la distinción entre "arte" y "vida". Y sea cual sea la historia del arte, el artista y lo estético, no sólo tendría que otorgar un lugar importante a los cambios institucionales y social sino que es necesario contrastar el proceso transcurrido desde el siglo XVIII con el estado 
presente y prestar especial atención a los esfuerzos por superar las polaridades típicas del moderno sistema de las bellas artes.

Vivimos un momento cultural en el que casi cualquier cosa es considerada "arte". Una de las razones que explica el auge de esta calificación es la vieja aspiración de que "arte" y vida se reconcilien. Si queremos entender el auge de lo artístico como categoría y su propósito evidente de reconciliar arte y vida, hay que investigar cómo se han originado las ideas modernas y las instituciones de las bellas artes. El arte comprendido como tal es una mera invención europea que apenas tiene doscientos años. Con anterioridad teníamos un sistema del arte más utilitario que duró unos dos mil años, seguramente, cuando nuestra invención actual desparezca surgirá un tercer sistema de las artes.

Por desgracia la historia de los pueblos, las antologías o las exposiciones en museos tienden a estimular nuestra natural inclinación a considerar cualquier cosa que venga del pasado en función de cómo sea en el presente y dejan de lado las diferencias de caso (Shiner, 2004, p. 22). De este modo las reproducciones de obras Renacentistas que inundan las más prestigiosas instituciones culturales o los libros de textos, fueron concebidos originalmente para un lugar o propósito determinado. Asimismo, las obras de Shakespeare no fueron escritos como textos definitivos e intemporales, sino que eran guiones que podían ser modificados durante su interpretación en un escenario popular.

En el siglo XVIII se estableció una distinción significativa en el concepto tradicional de arte. Tras significar durante dos mil años toda actividad humana realizad con habilidad y gracia, el concepto se descompuso en la nueva categoría de las bellas artes (poesía, arquitectura, pintura y música), en oposición a la artesanía y artes populares. A partir de esta época se comenzará a hablar de bellas artes, materia de inspiración y genio.

Las artes populares demostrarían la habilidad del artífice para aplicar determinadas reglas a sus obras y ser capaza de entretener al público. Cuando durante el siglo XIX se abandona el uso de adjetivo "bello" para referirse a las artes y se empieza a hablar de artes solamente por contraste con la propia artesanía. Pero la producción de hoy en día ¿puede ser considerada realmente como arte? ¿Pertenece a la categoría del arte como objeto bello?

\section{REFERENCIAS}

Abrams, M. H. (1989). Doing things with texts: Essays in Criticism and Critical Theory. Nueva York: W. W. Norton.

Acaso, M. (2006). El lenguaje visual. Barcelona: Paidós.

Aguirre, M. E. (2009). Los senderos del arte, la formación y la educación artística. Notas para un deslinde, en Revista Educación y Pedagogía, 21(55), 15- 29.

Alcina, J. (1982). Arte y Antopología. Madrid: Alianza. 
Arañó, J. C. (1994). Arte, educación y creatividad. Pixel-Bit: Revista de medios y educación. Recuperado de

http://www.sav.us.es/pixelbit/pixelbit/articulos/n2/n2art/art25.htm

Arnheim, R. (1986). Arte y percepción visual. Madrid: Alianza.

Calvo Serraller, F. (2011) Extravíos. Madrid: Fondo Cultura Económica.

Danto, A. (1997). Después del fin del arte. Barcelona: Paidós.

Delgado, J. (2003). La expresión plástica como producto creativo del lenguaje visual. Reflexiones acerca de su integración curricular. Creatividad y Sociedad, 3, 4953.

Efland, A. (2002). Art and cognition. Integrating the visual arts in the curriculum. Nueva York: Teachers College.

Eisner, E. W. (1995). Educar la visión artística. Barcelona: Paidós.

Eisner, E. W. (2004). Las artes y la creación de la mente. Barcelona: Paidós.

Eisle, C. (1987). Every Painter Paints Himself: Art History as Biography and Autobiography. Social Research, 54, 73-99.

Engel, M. y Dobbs, S. (1976). The future of aesthetic education. Art Education, 29(3), 5-8.

Gadamer, H. G. (1967). Verdad y método. Valladolid: Sígueme.

Gallego, J. (1976). El pintor, de artesano a artista. Granada: Diputación Provincial de Granada.

Gelbach, R. D. (1990). Art Education: Issues in Curriculum and Research. Educational Researcher, 19(17), 19-25.

Gombrich, E. H. (1984). La historia del Arte. Madrid: Phaidon.

Habermas, J. (1987). Teoría de la acción comunicativa. Madrid: Taurus.

Hargreaves, A. (1996). Profesorado, cultura y postmodernidad. Madrid: Morata.

Harris, M. (1990). Antropología cultural. Madrid: Alianza.

Hauser, A. (1975). Sociología del arte. Madrid: Guadarrama.

Linton, R. (1945). The cultural background of personality. New York: AppletonCentury Crofts. 
Locke, S. (1991). Depth Hermeneutics: Some problems in application to the public understanding of science. Sociology, 25(3), 375- 394.

Lowenfeld, V. (1987). Desarrollo de la capacidad creadora. Madrid: Síntesis.

Panofsky, E. (2004). Idea, contribución a la historia de la teoría del arte. Madrid: Cátedra.

Read, H. (1970). Arte y Sociedad. Barcelona: Península.

Schwarcz, V. (2006). El arte como construcción de conocimiento. Dicotomía con el conocimiento científico, en Academia Nacional de Educación. Recuperado de http://www.acaedu.edu.ar/espanol/paginas/novedades/jornadaarte2006/Violeta SAranguren.doc

Shiner, L. (2004). La invención del arte. Una historia cultural. Barcelona: Paidós.

Sohm, P. (2002). Caravaggio's Deaths, en Art Bulletin, 84, 459- 467.

Tatarkiewicz, W. (1987). Historia de la estética. Madrid: Akal.

Wittkower, R. y Wittkower, M. (2006). Born Under Saturn: The Character and Conduct of Artists: a Documented History from Antiquity to the French Revolution. Nueva York: Review Books. 